\title{
Analysis of epidemiological and clinical characteristics of inflammatory bowel disease over 15- year period
}

\section{Abstract}

Background and Aims: The prevalence of inflammatory bowel disease (IBD) is increasing rapidly in China. We aimed to explore the trends in epidemiological and clinical characteristics of IBD in Eastern China over the 15-year period.

Methods: This is a multi-center retrospective study. Newly diagnosed IBD cases from January 1995 to December $2009(n=427)$ in Eastern China were included. Study protocol was approved by Institutional Review Board. Disease severity was assessed by Montreal classification. It was divided into two periods: 1995-2004 and 2005-2009. The epidemiological and clinical characteristics of ulcerative colitis (UC) and Crohn's disease (CD) were compared in these two periods, respectively.

Results: The mean inpatient CD incidence had 2.5 fold increment with $\mathrm{p}<0.05$ while incidence of UC did not change significantly over the two periods $(\mathrm{p}>0.05)$. The incidence growth of CD is significantly associated with the growth of gross domestic product (GDP) in China $(\mathrm{P}<0.001)$. There were no statistically significant difference regarding the mean age at diagnosis, gender ratio and mortality rate $(\mathrm{P}>0.05)$ between the two periods among both UC and CD. Meanwhile, the rate of applications of immunomodulators and biologics was higher in 2005-2009 than those in 1995-2004 $(\mathrm{P}<0.05)$.

Conclusions: During 1995 - 2009, age at diagnosis, gender and the familial occurrence of IBD did not change significantly in Eastern China. The incidence in inpatient CD has increased 2.5 fold and significantly associated with the GDP growth. This study provides insight into the possible local epidemiological and clinical patterns of IBD.

Keywords: change, epidemiology, clinical characteristics, inflammatory bowel disease
Volume 2 Issue 2 - 2015

\author{
Nelson Carrillo, Miguel Perez Central \\ Department of Gastroenterology, University of Venezuela, \\ Venezuela
}

\begin{abstract}
Correspondence: Nelson Carrillo, University of Venezuela, Libertador Avenue, Angostura Building, 7 Floor, Office 7B, Caracas, Venezuela, Tel 58-212-7632202, Fax 58-212-9917903, EmailncpI4I@yahoo.com
\end{abstract}

Received: February 0I, 2015 | Published: April 7, 2015
Abbreviations: UC, ulcerative colitis; $\mathrm{CD}$, crohn's disease; IBD, inflammatory bowel disease; 5-ASA, 5-aminosalicylic acid; SASP, salazosulfapyridine; GDP, gross domestic product; SPSS, statistical product and service solutions

\section{Introduction}

Ulcerative colitis (UC) and Crohn's disease (CD) are two diseases under the umbrella of Inflammatory Bowel Disease (IBD). IBD has been traditionally considered a "western" disease. The highest annual incidence of UC reached 24.3 per 100,000 person-years in Europe, 19.2 per 100,000 person-years in North America, and 6.3 per 100,000 person-years in Asia and the Middle East, while that of CD was 12.7 per 100,000 person-years in Europe, 20.2 per 100,000 person-years in North America, and 5.0 person years in Asia and the Middle East. The incidence of IBD in Asia seems to be in a relatively low level, but it has progressively increased. A population-based study in Korea has indicated the mean annual incidence rates of $\mathrm{CD}$ and $\mathrm{UC}$ in 2001-2005 were increased by 25 and 8-fold, respectively, compared with those in 1986-1990. ${ }^{2}$ China has also experienced a steadily incidence growth with an 8.5-fold increase in 2002-2007 compared with 1989-1994, and there is a predominant annual increase in IBD since 2004. ${ }^{3}$ The increasing incidence of IBD is posing an emerging health issue in China, which has attracted much attention from gastroenterologists all over the country. ${ }^{4,5}$ However, long-term studies about the chronological changes in epidemiology and clinical nature of IBD currently are rare in China. In this study, we aimed to explore the trends in epidemiological and clinical characteristics of IBD in Eastern China. We analyzed 427 hospitalized patients diagnosed with IBD in 3 hospitals in Zhejiang province located in Eastern China from 1995 to 2009. Our study may provide an insight into the changing epidemiological and clinical patterns of IBD and offer potential opportunities to identify the etiological factors in Eastern China.

\section{Materials and methods}

\section{Patients}

This study included all hospitalized newly diagnosed IBD cases in three hospitals in Zhejiang province located in Eastern China from 1 January 1995 to 31 December 2009. The three hospitals are geographically distributed in the west, north and east of Zhejiang province. 427 patients were enrolled. They all meet the LennardJones criteria for diagnosis. ${ }^{6}$ Patients with a non-IBD diagnosis such as infectious colitis, bacillary dysentery, amebiasis, chronic schistosomiasis, intestinal tuberculosis, ischemic colitis and radiation colitis were excluded. The admission time of all patients were divided into two periods, 1995-2004 (A) and 2005-2009 (B). The patients were further categorized into two sub-groups within each period based on UC and CD forms (Group A1: UC, 1995-2004, n=116; Group B1: UC, 2005-2009, $n=135$; GroupA2: CD, 1995-2004, n=62; Group B2: CD, 2005-2009, $n=114$ ). 


\section{Assessment of diseases}

Montreal classification ${ }^{7}$ was applied for both UC and CD. The extent of ulcerative colitis (UC) was classified as Ulcerative proctitis (E1), Left sided UC (E2), and Extensive UC (E3), while the severity of UC was divided into mild UC (S1), moderate UC (S2) and severe UC (S3). Patients with CD were classified by age of diagnosis (A1: $\leq 16$ years; A2: 17-40years; A3: $>40$ years), location of disease (L1: ileal; L2: colonic; L3: ileocolonic; L4: isolated upper disease), and disease behavior (B1: non-stricturing, nonpenetrating; B2: stricturing; B3: penetrating; $p$ : perianal disease modifier).

\section{Data collection}

In January 2000, we established an electronic database for all hospitalized patients in the three hospitals. It contained medical records from all of patients hospitalized thereafter. Additionally, paper medical records for all hospitalized patients between January 1995 and December 1999 from the medical record department were added to this database. Newly diagnosed IBD cases between 1 January 1995 to 31 December 2009 had been identified and their demographic, clinical profiles and treatment patterns had been collected retrospectively, including: gender, family history, age of diagnosis, severity, location, activity of disease, the laboratory examinations, the endoscopy, radiological, surgical and pathological records, the extra-intestinal manifestations and complications; the medication information of Salazosulfapyridine (SASP)/5-aminosalicylic acid (5-ASA), corticosteroids, immunomodulators and biological agents. Each patient has an individual medical records code, and for who had been hospitalized more than 2 times, only the first was taken into account.

\section{The study design}

This is a multi-center, retrospective and observational study. Data were extracted from the electronic database. Study protocol was approved by local Institutional Review Board. Clinical characteristics of the four groups mentioned above were compared. We compared epidemiological and clinical characteristics among the cases of each IBD type between two periods to seek potential shifts in epidemiological and clinical patterns.

\section{Statistical analysis}

The incidence in inpatients of IBD from 1995 to 2009 were calculated using the total number of new inpatients in the hospitals in one year as the denominator and the number of new cases of IBD inpatients of the same year as the numerator. The date when IBD was diagnosed rather than the date of symptom onset was used to determine incidence in inpatients in order to avoid recall bias. Incidence in inpatients was expressed as the number of patients per 1,000,000. Statistical analyses were performed by SPSS V 16.0 (Statistical Product and Service Solutions). The continuous data were expressed as mean values and standard deviation. The categorical data were expressed by percentages. One-way ANOVA test was performed to analyze the continuous data and the chi-square test or the Fisher's exact test was used to analyze the categorical data. Spearman rank correlation was used to identify the correlations between gross domestic product (GDP) and incidence in inpatients. $\mathrm{P} \leq 0.05$ was considered statistically significant.

\section{Results}

\section{Overall characteristics of IBD patients}

$251(58.8 \%) \mathrm{UC}$ and $176(41.2 \%) \mathrm{CD}$ patients were diagnosed during 1995-2009 in the three hospitals in Eastern China. All of them were ethnically Chinese. Their characteristics were summarized in Table 1 and Table 2.

Table I Characteristics of UC patients

\begin{tabular}{|c|c|c|c|}
\hline \multicolumn{2}{|c|}{ UC $(n=25 I)$ Characteristics } & \multirow[t]{2}{*}{$A I(n=\mid 16)$} & \multirow[t]{2}{*}{$B I(n=135)$} \\
\hline Male/female & $128 / 123$ & & \\
\hline $\begin{array}{l}\text { Median diagnosis age, } \\
\text { years (range) }\end{array}$ & $48(15-80)$ & & \\
\hline \multicolumn{4}{|l|}{ Extent n (\%) } \\
\hline EI(Ulcerative proctitis ) & $27(10.8)$ & $\mathrm{II}(9.5)$ & $16(11.8)$ \\
\hline E2( Left sided UC ) & $105(41.8)$ & $46(39.6)$ & $59(43.8)$ \\
\hline E3( Extensive UC ) & $119(47.4)$ & $59(50.9)$ & $60(44.4)$ \\
\hline \multicolumn{4}{|l|}{ Severity n (\%) } \\
\hline SI( Mild UC ) & $99(39.5)$ & $46(39.7)$ & $53(39.3)$ \\
\hline S2( Moderate UC) & $106(42.2)$ & $50(43.1)$ & $56(4 I .5)$ \\
\hline S3( Severe UC ) & $46(18.3)$ & $20(17.2)$ & $26(19.2)$ \\
\hline \multicolumn{4}{|l|}{ Clinical type n (\%) } \\
\hline The initial & $76(30.3)$ & $49(42.2)$ & $27(20.0)$ \\
\hline chronic relapsed & $153(61.0)$ & $55(47.4)$ & $98(72.6)$ \\
\hline chronic persistent & $21(8.3)$ & $12(10.4)$ & $9(6.7)$ \\
\hline The fulminant & I (0.4) & $0(0.0)$ & $\mathrm{I}(0.7)$ \\
\hline Colectomy n (\%) & $19(7.6)$ & $\mathrm{II}(9.5)$ & $8(5.9)$ \\
\hline Mortality n (\%) & I $(0.4)$ & $0(0)$ & $\mathrm{I}(0.7)$ \\
\hline Family history n (\%) & I $(0.4)$ & $\mathrm{I}(0.9)$ & $0(0)$ \\
\hline \multicolumn{4}{|l|}{ Drug therapy n (\%) } \\
\hline SASP/5ASA & $226(90.0)$ & $98(84.5)$ & I28(94.8) \\
\hline Corticosteroids & $103(4 \mid .0)$ & $4 I(35.3)$ & $62(45.9)$ \\
\hline $\begin{array}{l}\text { Immunosuppressive } \\
\text { agents }\end{array}$ & $12(4.8)$ & $\mathrm{I}(0.9)$ & II (8.I) \\
\hline Biological agents & $3(1.2)$ & $0(0)$ & $3(8.1)$ \\
\hline
\end{tabular}

Note: The distribution of clinical characteristics, the rate of colectomy, mortality, familial aggregation and the drug therapeutic status of IBD were calculated according to the number of inpatients.

\section{Incidence of IBD in inpatients population over time and correlation with GDP}

The overall incidence in inpatients of $\mathrm{CD}$ increased with 2.5 fold while the mean incidence in inpatients of UC displayed no significant 
difference $(\mathrm{P}>0.05)$. Meanwhile, the GDP grew steadily (Figure 1). The annual IBD incidence in inpatients and Gross Domestic Product (GDP) of Zhejiang province during 1995-2009 were shown in Table 3. The UC/CD ratio was decreased $(\mathrm{P}<0.05)$ from 1.87 in $1995-2004$ (group A1/A2) to 1.18 in 2005-2009 (group B1/B2). The incidence in inpatients of $\mathrm{CD}$ has caught up with or even surpassed that of UC since 2007. For Group A1 (UC 1995-2004, n=116) and Group B1 (UC 2005-2009, $n=135$ ), the mean hospitalization rates were 833/10 and $956 / 10^{6}$ respectively. There was no significant increase in the hospitalization rates during the study period for $\mathrm{UC}(\mathrm{P}=0.537)$. By contrast, for Group A2 (CD 1995-2004, n=62) and Group B2 (CD 2005-2009, $\mathrm{n}=114$ ), the hospitalization rates were $383 / 10^{6}$ and $954 / 10^{6}$ respectively with the increment of 2.5 time $(\mathrm{P}=0.002)$. However, only the incidence in inpatients of CD (Figure 2b), instead of UC Figure 2(A), displayed a significant positive association with GDP ( $\mathrm{r}=0.844$, $\mathrm{P}<0.001)$.

Table 2 Characteristics of $C D$ patients

\begin{tabular}{|c|c|c|c|}
\hline$C D(n=\mid 76)$ Characteristics & & $A 2(n=62)$ & $B 2(n=|| 4)$ \\
\hline & & $1995-2004$ & $2005-2009$ \\
\hline Male/female & $|05 / 7|$ & $37 / 25$ & $68 / 46$ \\
\hline Mean diagnosis age, years (range) & $34(9-7 I)$ & $34.8 I \pm 14.3$ & $34.23 \pm 12.9$ \\
\hline \multicolumn{4}{|l|}{ Age at diagnosis } \\
\hline AI(below I6 y) & $16(9.1)$ & $6(9.7)$ & $10(8.8)$ \\
\hline A2 (17y-40y) & $116(65.9)$ & $39(62.9)$ & $77(67.5)$ \\
\hline A3(above 40y) & $44(25.0)$ & $17(27.4)$ & $27(23.7)$ \\
\hline \multicolumn{4}{|l|}{ Location } \\
\hline LI (ileal) & $45(25.6)$ & $20(32.3)$ & $25(21.9)$ \\
\hline L2(colonic) & $37(21.0)$ & $13(21.0)$ & $24(21.2)$ \\
\hline L3(ileocolonic) & $83(47.2)$ & $25(40.3)$ & $58(50.9)$ \\
\hline L4(isolated upper disease) & II (6.2) & $4(6.4)$ & $7(6.1)$ \\
\hline \multicolumn{4}{|l|}{ Behavior } \\
\hline BI (non-structuring, non-penetrating) & $97(55.1)$ & $23(37.1)$ & $74(64.9)$ \\
\hline B2 (structuring) & $60(34.1)$ & $28(45.2)$ & $32(28.1)$ \\
\hline B3 (penetrating) & $19(10.8)$ & $\mathrm{II}(\mathrm{I7.7})$ & $8(7.0)$ \\
\hline $\mathrm{P}$ (perianal disease modifier) & $61(34.7)$ & $17(27.4)$ & $44(38.6)$ \\
\hline Colectomy n (\%) & $4 \mathrm{I}(23.3)$ & $20(32.3)$ & $21(18.4)$ \\
\hline Mortality n (\%) & $4(2.3)$ & $3(4.8)$ & $\mathrm{I}(0.9)$ \\
\hline Family history n (\%) & $3(1.7)$ & $0(0)$ & $3(2.6)$ \\
\hline \multicolumn{4}{|l|}{ Drug therapy n (\%) } \\
\hline SASP/5ASA & $162(92.0)$ & $56(90.3)$ & $106(93.0)$ \\
\hline Corticosteroids & $82(46.6)$ & $25(40.3)$ & $57(50.0)$ \\
\hline Immunosuppressive agents & $43(24.4)$ & $8(12.9)$ & $35(30.7)$ \\
\hline Biological agents & $12(6.8)$ & $0(0)$ & $12(6.8)$ \\
\hline
\end{tabular}

Note: The distribution of clinical characteristics, the rate of colectomy, mortality, familial aggregation and the drug therapeutic status of IBD were calculated according to the number of inpatients. 
Table 3 The distributions of incidence in inpatients with IBD patients and the Gross Domestic Product (GDP) of Zhejiang rovince from I995 to 2009

\begin{tabular}{|c|c|c|c|c|c|}
\hline CalendarYear & Total hospitalization* & IBD, n (/106) & UC, $n(/ 106)$ & $C D, n(/ 106)$ & GDP (hundred Million yuan) \\
\hline 1995 & 4,845 & $5(1032)$ & $4(826)$ & $\mathrm{I}(206)$ & 3557.55 \\
\hline 1996 & 5,930 & $2(337)$ & $2(337)$ & $0(0)$ & 4188.53 \\
\hline 1997 & 8,312 & $2(24 I)$ & $2(24 I)$ & $0(0)$ & 4686.11 \\
\hline 1998 & $|0,34|$ & $7(677)$ & $5(484)$ & $2(193)$ & 5052.62 \\
\hline 1999 & 12,656 & $15(\mid 185)$ & $12(948)$ & $3(237)$ & 5443.92 \\
\hline 2000 & 15,006 & $29(1933)$ & $21(1399)$ & $8(533)$ & 6141.03 \\
\hline 2001 & 16,654 & $31(|86|)$ & $21(1261)$ & $10(600)$ & 6898.34 \\
\hline 2002 & 21,563 & $29(1345)$ & 14(649) & $15(696)$ & 8003.67 \\
\hline 2003 & 23,307 & $46(1974)$ & $29(1244)$ & $17(729)$ & 9705.02 \\
\hline 2004 & 26,657 & $42(1576)$ & $25(938)$ & $17(638)$ & 11648.7 \\
\hline 2005 & 27,718 & $47(1696)$ & $24(866)$ & $23(830)$ & 13417.68 \\
\hline 2006 & 30,828 & $68(2206)$ & $40(1298)$ & $28(908)$ & $157 \mid 8.47$ \\
\hline 2007 & 33,765 & $70(2073)$ & $34(1007)$ & $36(1066)$ & 18753.73 \\
\hline 2008 & 38,309 & $58(15 \mid 4)$ & $33(86 I)$ & $25(653)$ & 21462.69 \\
\hline 2009 & 44,177 & $91(2060)$ & $33(747)$ & $58(|3| 3)$ & 22990.35 \\
\hline
\end{tabular}

* Total hospitalization indicates the number of all hospitalization patients in the studied hospitals.

Note:The hospitalization rates of IBD were calculated according to the number of cases for patient admission.

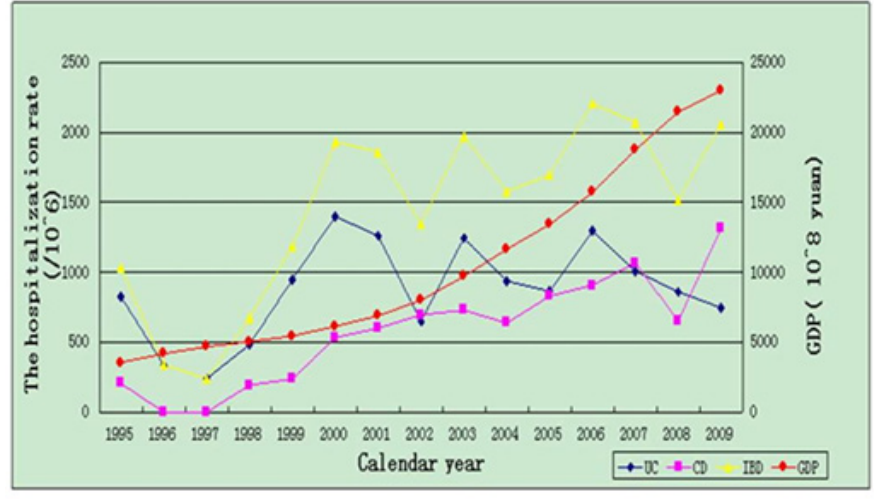

Figure I The trends of incidence in inpatients of IBD and Gross domestic product (GDP) in Zhejiang province with calendar year from 1995 to 2009.

\section{Comparison of clinical characteristics}

\section{Disease location and severity}

Extensive colitis (E3) and Left sided colitis (E2) were common for UC while proctitis (E1) was less common site Figure 3(A). The mild (S1) and moderate colitis (S2) accounted for about eighty percent of the UC cases Figure 3(B). There were no significant differences in terms of patterns of location $(p=0.57)$ and severity $(p=0.93)$ between the two periods, 1995-2004 and 2005-2009 (Figure 3a \& $3 b)$. However, the proportion of patients with relapse increased from $47.4 \%$ in group A1 (UC 1995-2004) to $72.6 \%$ in group B1 (UC 20052009). Conversely, the proportion of the initial type (Based on specific
Chinese classification as: initial, chronic relapsed, chronic persistent and fulminant) decreased from $42.2 \%$ to $20.0 \%$ (Figure $3 \mathrm{c}, \mathrm{P}<0.001$ ). The distribution of location of CD was $32.2 \%$ ileal (L1), $21.0 \%$ colonic (L2) and 40.3\% (L3) in group A2 (CD 1995-2004) while it was $21.9 \%(\mathrm{~L} 1), 21.2 \%$ (L2) and $50.9 \%$ (L3) in group B2 (CD 2004-2009) Figure 4(B). The distributions of both age at diagnosis $(\mathrm{P}=0.82)$ and location ( $\mathrm{P}=0.43$ ) of $\mathrm{CD}$ remained unchanged Figure $4(\mathrm{~A} \& \mathrm{~B})$. The proportions of patients with non-stricturing/ non-penetrating behavior increased significantly, from $37.1 \%$ in group A2 to $64.9 \%$ in group $\mathrm{B} 2$, while the proportions of the stricturing decreased from $45.2 \%$ in group A2 to $28.1 \%$ in group B2; penetrating types were decreased from $17.7 \%$ in group $\mathrm{A} 2$ to $7.0 \%$ in group $\mathrm{B} 2$ Figure $4(\mathrm{C}), \mathrm{P}=0.001$ ).

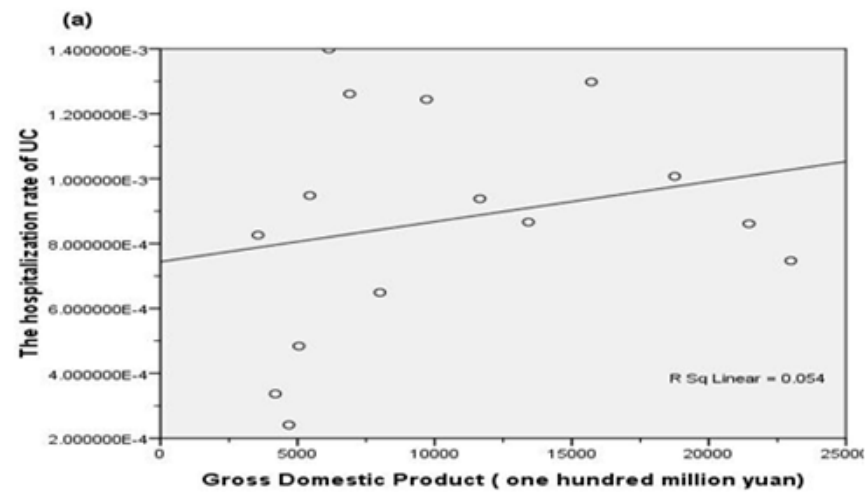

Figure 2A 


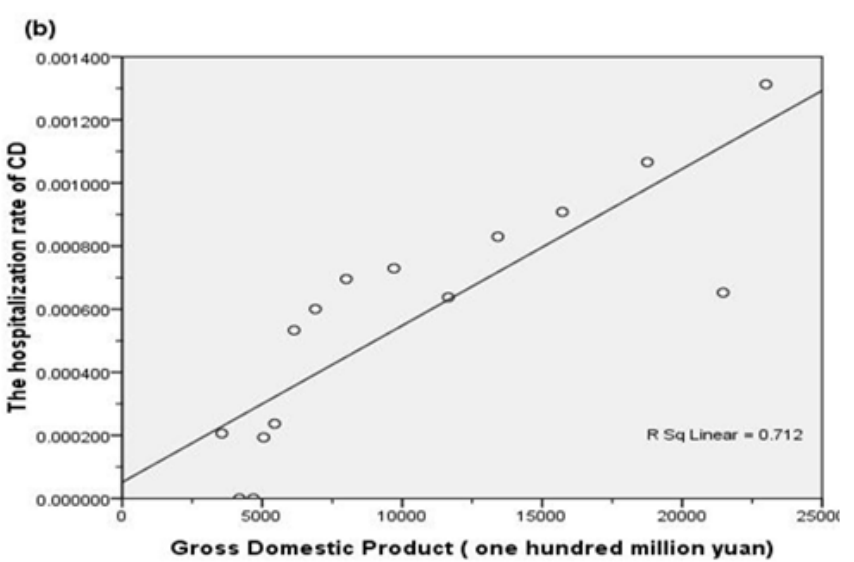

Figure 2 The association of gross domestic product (GDP) with incidence in inpatients of UC (a) and CD (b) patients

\section{Gender}

Among UC patients, 58 males and 58 females were diagnosed during 1995-2004 (group A1), while 70 males and 65 females were diagnosed during 2005-2009 (group B1). Group A1 and B1 displayed no significant difference in gender ratio $(\mathrm{M} / \mathrm{F}$ : 1 vs $1.08, \mathrm{P}=0.77)$. There were 37 males and 25 females in 1995-2004 (group A2), as well as 68 males and 46 females in 2005-2009 (group B2), were diagnosed with $\mathrm{CD}$. The gender ratio of $\mathrm{CD}$ patients did not change significantly (M/F: 1.48 vs $1.48, \mathrm{P}=1.0)$.

\section{Age at diagnosis}

The overall mean age at diagnosis was $47.53 \pm 14.1$ years for UC, and $34.53 \pm 13.4$ years for $\mathrm{CD}$. The distribution of age at diagnosis showed a main peak in the fifth decade for UC (Supplemental Figure 1(A), and a main peak in the third decade for CD (Supplemental Figure 1(B). There was no significant change of age at diagnosis for either UC or CD between these two periods. In 1994-2004, the mean age at diagnosis of $U C$ was $47.01 \pm 14.8$ years, while it was $47.97 \pm 13.6$ years in 2005-2009 $(\mathrm{P}=0.59)$. Similarly, the mean age at diagnosis for $\mathrm{CD}$ was $34.81 \pm 14.3$ years in $1994-2004$ and $34.23 \pm 12.9$ years in 2005 $2009(\mathrm{P}=0.78) .62 .9 \%$ of $\mathrm{CD}$ patients in group A2 (CD 1995-2004) and $67.5 \%$ in group B2 (CD 2005-2009) were diagnosed between 17 to 40 years old Figure $4(\mathrm{~A})$.

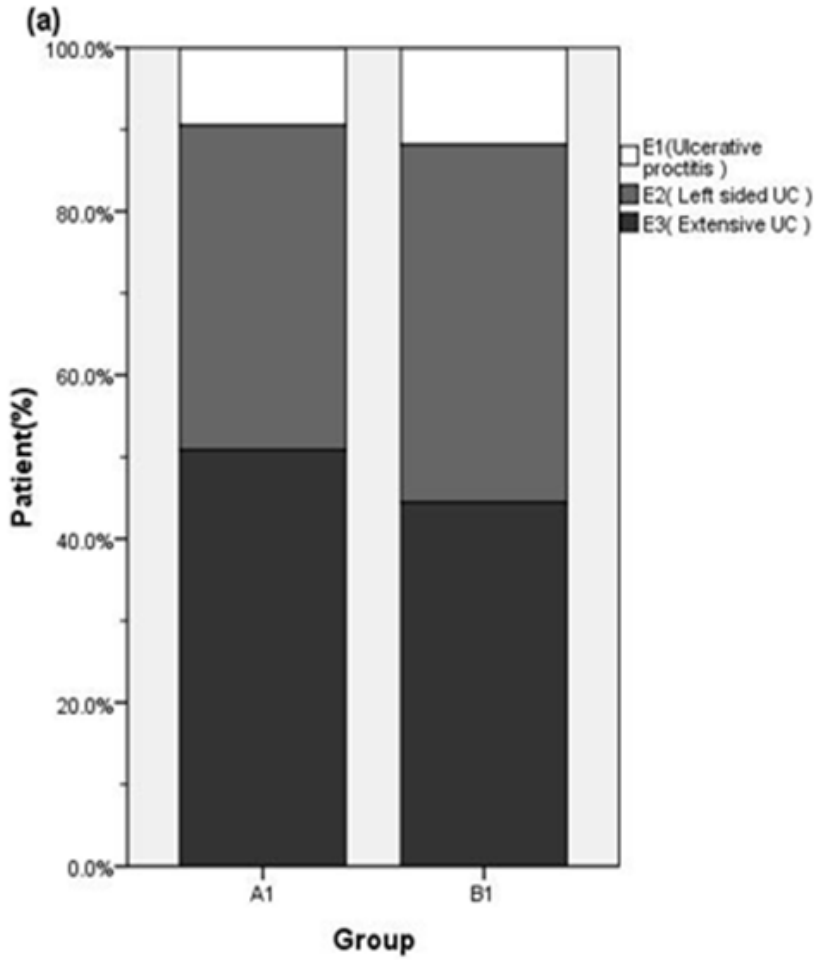

Figure 3A

\section{(b)}

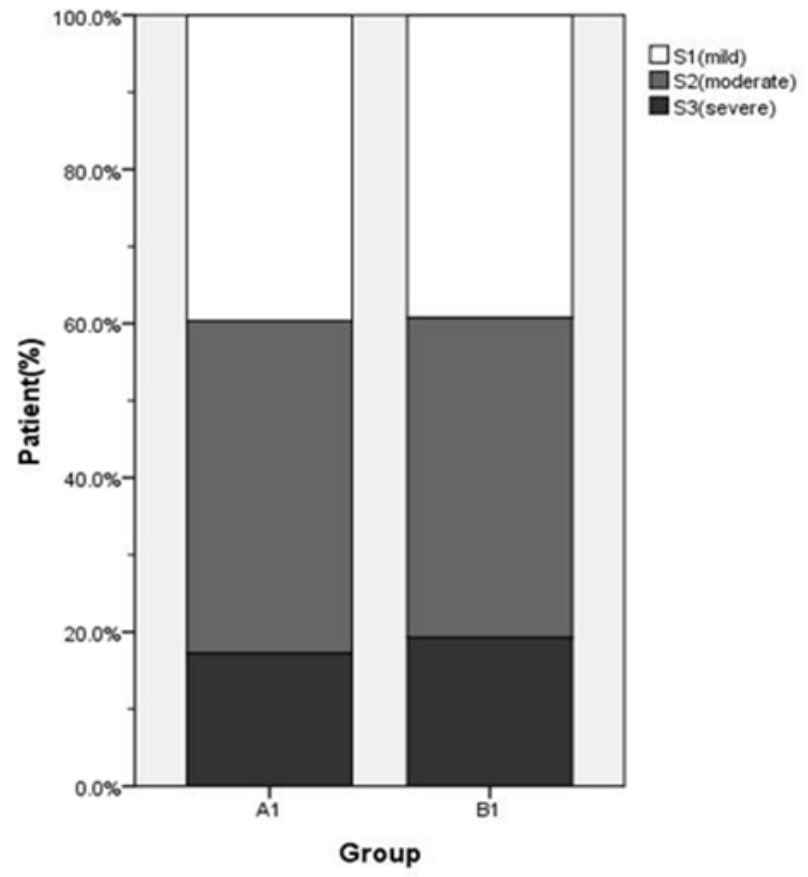

Figure 3B 


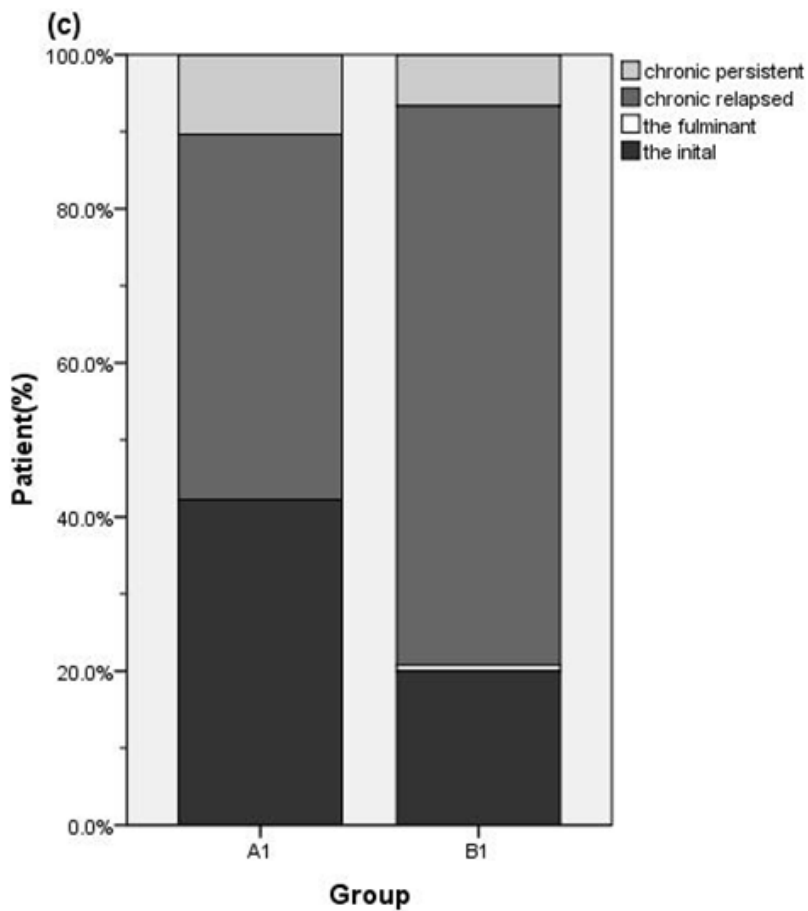

Figure 3 Distributions of the extent (a) severity (b) and clinical type (c) of UC according to the admission year (AI: |995-2004; BI: 2005-2009).The proportion of chronic relapsed type increased while the initial type decreased during the study period. $(P<0.00 \mathrm{I})$.

\section{Fig $4($ a)}

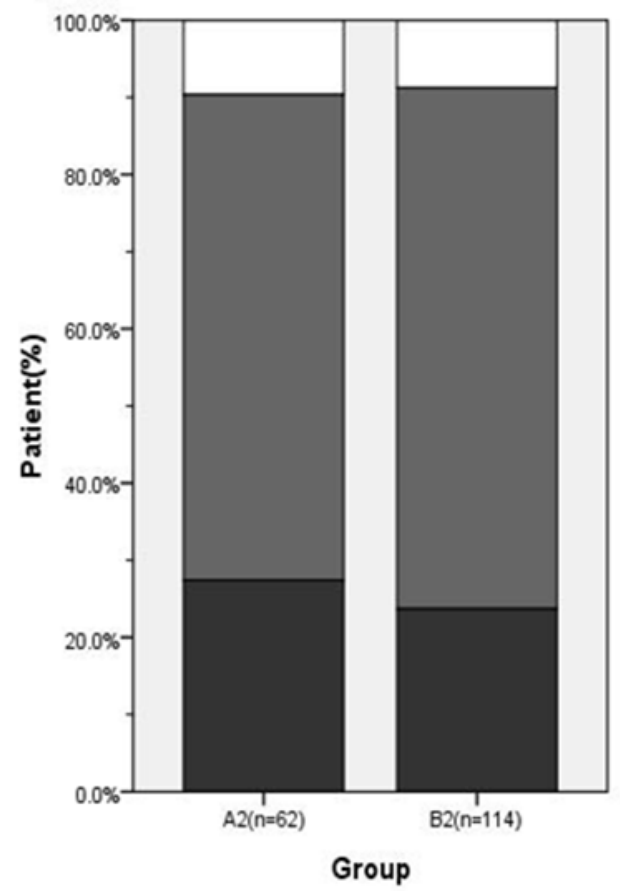

Fig 4(b)

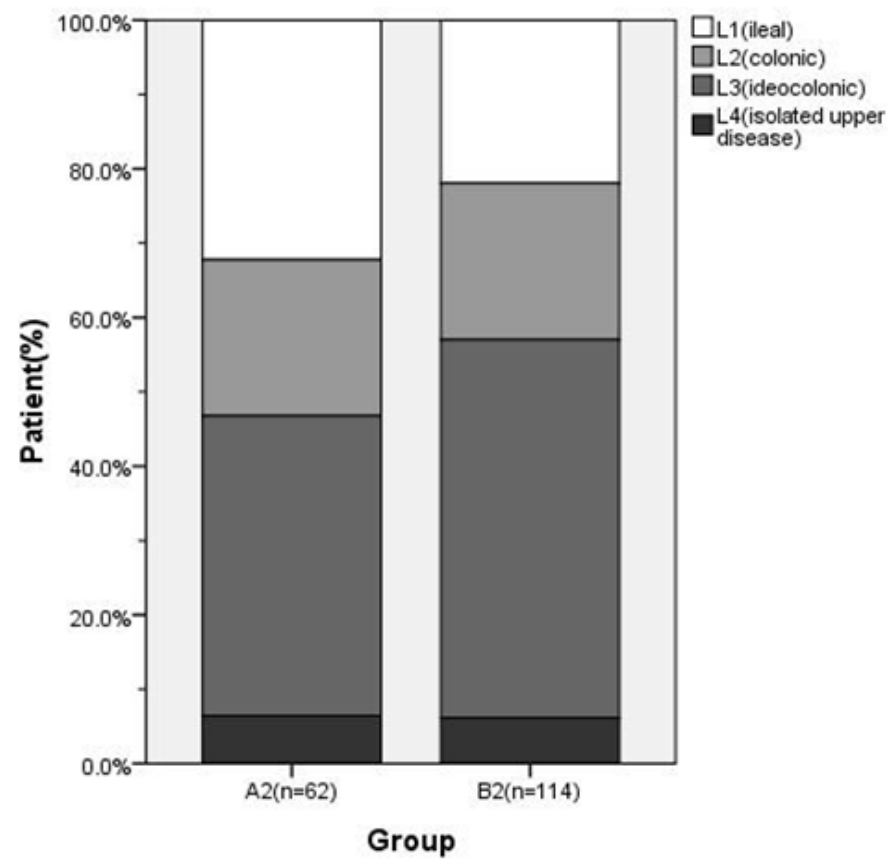

Figure 4A

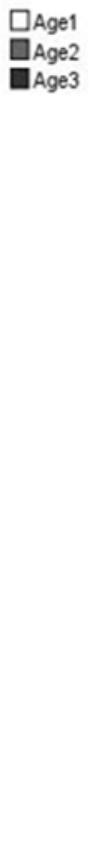

Figure 4B

Citation: Cao Q,Wan S, Lei M, et al.Analysis of epidemiological and clinical characteristics of inflammatory bowel disease over 15- year period. Gastroenterol Hepatol Open Access. 20 15;2(3):84-93. DOI: 10.15406/ghoa.20 I5.02.0004 I 


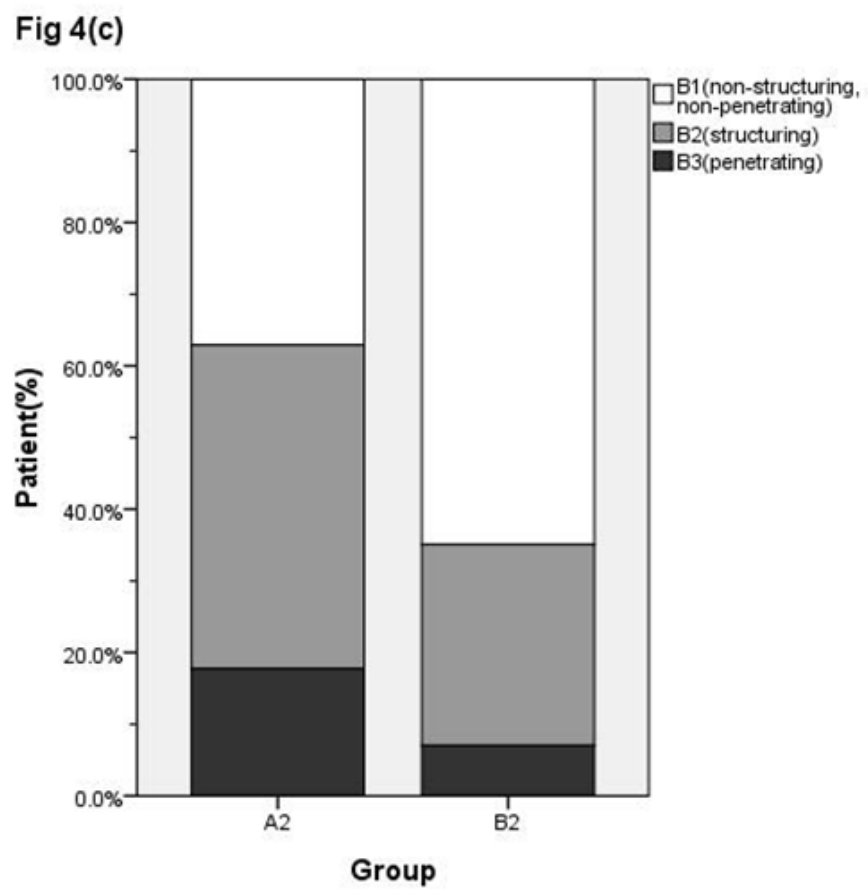

Figure 4 Distributions of the age (a) location (b) and behavior (c) of CD according to the admission year (A2: 1995-2004; B2:2005-2009). The proportion of $\mathrm{BI}$ (non-structuring non-penetrating) increased while the B3 (penetrating) type decreased during the study period $(P=0.00 \mathrm{I})$.

(a)

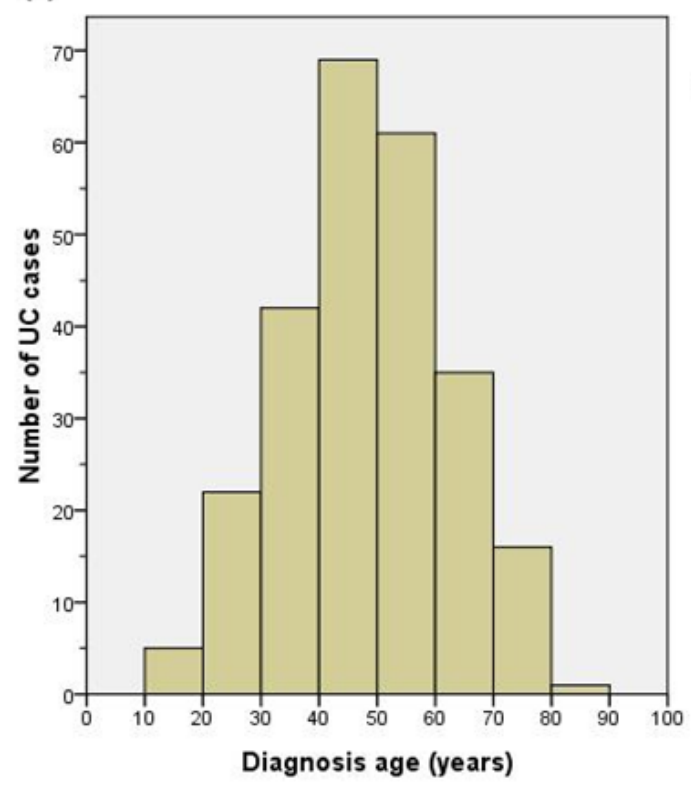

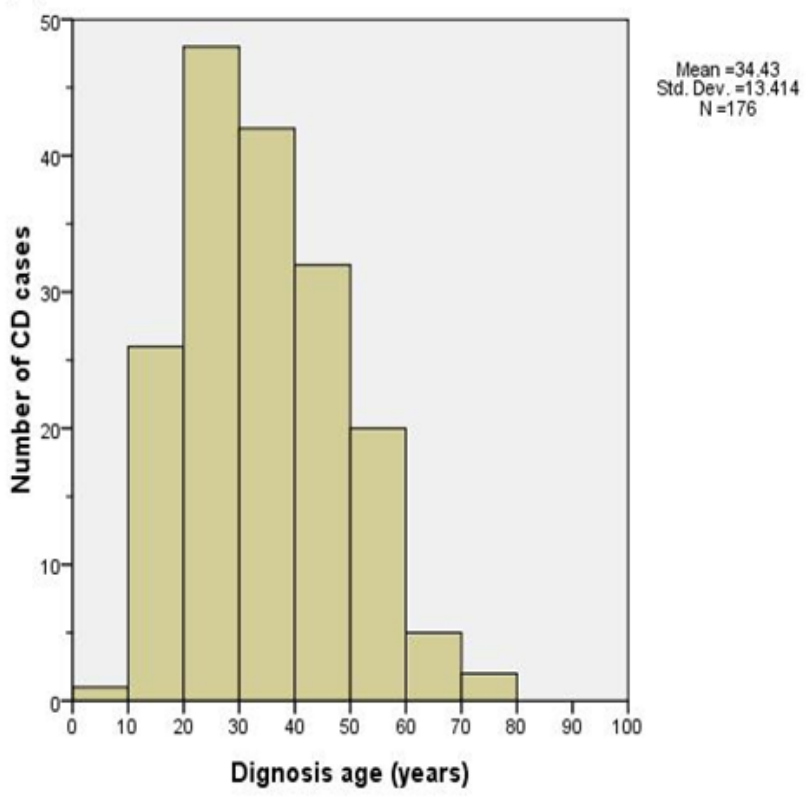

(b)

Dignosis age (years)

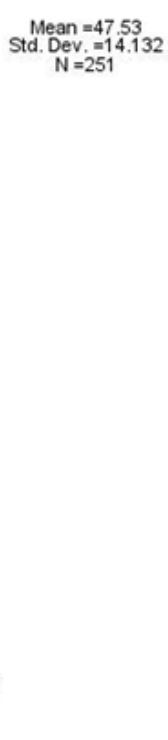




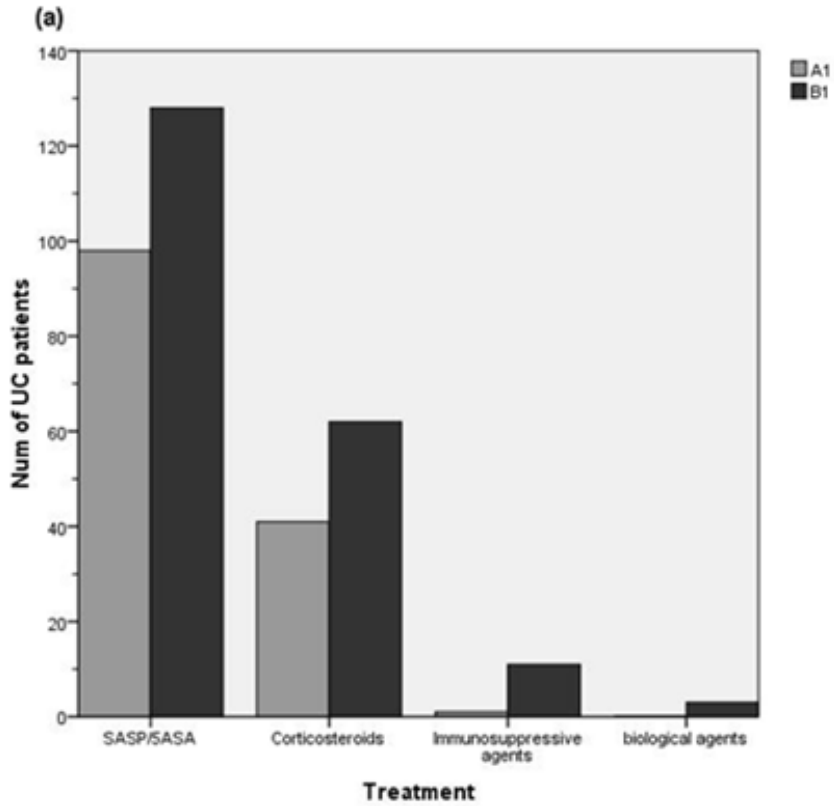

Supplemental Figure 2A

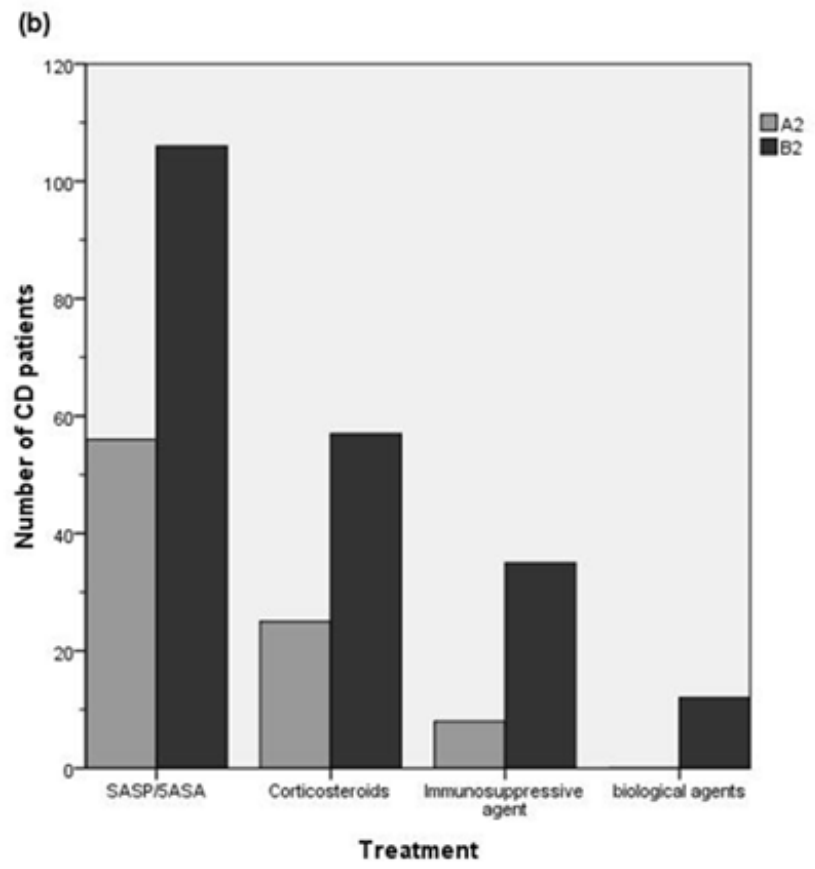

Supplemental Figure 2 Drug therapeutic status of UC patients (a) and CD patients (b). The applications of SASP/5-ASA, corticosteroids, immunosuppressive agents and biological agents both increased in UC patients $(P=0.036$ with Fisher's exact test) and CD patients $(P=0.018$ with Fisher's exact test).

\section{Colectomy}

Colectomy was performed in $19 \mathrm{UC}$ patients and $41 \mathrm{CD}$ patients. There was no significant difference for the colectomy rates of UC patients in 1995-2004 (9.5\%) and 2005-2009 (5.9\%) with $\mathrm{P}=0.29$. By contrast, a lower colectomy rate of CD patient in 2005-2009 compared with the colectomy rate in $1995-2004(18.4$ vs $32.3 \% \mathrm{P}=0.04)$.

\section{Mortality}

Only one death occurred in UC patients which was from group B1 (UC 2005-2009) and died from hepatic failure (patient had primary sclerosing cholangitis-UC). There were four deaths in $\mathrm{CD}$ patients. Three of them occurred in group A2 (1995-2004) and one of them occurred in group B2 (2005-2009) (0.048 vs 0.0087, p<0.01). In detail, causes for death were intestinal perforation (1), intestinal hemorrhage and hemorrhagic shock (2) and toxic megacolon (1). Therefore the mortality from CD significantly decreased from 19952004 to 2005-2009.

\section{Family history}

Only one female UC patients (from A1 1995-2004) had a family history of father being diagnosed of UC. No family history was reported in group B1 (2005-2009). There was no significant difference in familial aggregation between the two groups $(\mathrm{P}=0.46)$. Meanwhile, three CD patients from group B2 (2005-2009) had a positive family history, and no CD patients from group A2 (1995-2004) had positive family history.

\section{Medications}

Among UC patients, the applications of the Salazosulfapyridine(SASP)/5ASA, Corticosteroids, immunosuppressive and biological agents in group B1 were higher compared with group A1 (Supplemental Figure $2 \mathrm{~A}, \mathrm{P}<0.05$ ). A similar tendency was observed in $\mathrm{CD}$ patients. The proportion of the SASP/5ASA, Corticosteroids, immunosuppressive and biological agents were increasing from group A2 to B2 (Supplemental Figure $2 \mathrm{~B}, \mathrm{P}<0.05)$.

\section{Discussion}

There are rapid increases of IBD cases in China during the last two decades. However, studies about chronological changes of IBD are scarce. In this study, we investigated the epidemiological and clinical characteristics trend in IBD patients based on our hospital registry database. The first large-scale multicenter study of hospitalized patients with IBD in China showed that the year-specific proportion of UC cases to all GI cases in 2001 was 2.11 times higher than in $1990 .{ }^{8}$ The year-specific ratio of $\mathrm{CD}$ to all hospitalized patients in 2003 was 2.78 -fold higher than that in $1990 .{ }^{9}$ In our study, the highest annual incidence in inpatients of UC was 5.8 fold higher than the lowest. However, the mean rate of UC in 2005-2009 did not increase significantly than that in 1995-2004. By contrast, the growth of incidence in inpatients of $\mathrm{CD}$ was particularly remarkable. This shift tendency in UC/CD ratio was also seen in some Asian and Western countries. In Korea, the UC/CD ratio decreased from 6.8 in 1986-1990 to 2.3 in 2001-2005..$^{2}$ In Olmsted, County, Minnesota, the prevalence of UC has decreased by $7 \%$ since 1991 , while the prevalence of $\mathrm{CD}$ has increased by about $31 \% .^{10}$ In Hungary, a sharp increase in incidence of UC and CD were seen from 1977 to 2001 as the ratio of $\mathrm{UC} / \mathrm{CD}$ incidence rates decreased from 4.05 to 2.35 during the observed periods. ${ }^{11}$ In northern France, the incidence of 
CD increased by $23 \%$ from 1988 to 1999 , while that of UC decreased by $17 \%$ during the same period. ${ }^{12}$ All of the above suggested that the incidence of $\mathrm{UC}$ has reached a plateau phase while $\mathrm{CD}$ becomes more prevalent. With the increasing incidence of IBD in China, the gap of incidence rates between China and western countries is diminishing.

GDP is used to measure the economic conditions of one country. In our study, we found the incidence in inpatients of $C D$ was consistent with the GDP growth, suggesting that the environmental factors may play a role in the pathogenesis of $\mathrm{CD}$. With the social and economic development in Zhejiang province in the past two decades, the emerging western lifestyle such as diet habit, increasing industrialization and urbanization may provide valuable clues to the increment of IBD. In addition, the better diagnostic techniques, the improvement in livelihood and healthcare, and the increased physician awareness of this disease have promoted the detect capability of CD cases. This phenomenon was also seen in some other Asian countries. The incidence rate of IBD increased rapidly in Japan in the 1960s and $1970 \mathrm{~s},{ }^{13}$ and in Korea the increase was seen in 1980s and 1990s. ${ }^{14}$ In American, the incidence and prevalence of $\mathrm{CD}$ has increased since the Second World War. ${ }^{15}$ It may test the hygiene hypothesis that there has been a fundamental change from a "dirty" lifestyle with high microbial exposure, to a "clean" lifestyle with low microbial exposure. ${ }^{16}$ The location of IBD in our study did not change obviously during the past 15 years, similar to our previously study in $2003 .{ }^{17}$ The pancolitis was the most common site of UC, while proctitis was less common. The most frequent locations of $\mathrm{CD}$ were the ileum and colon. These results are consistent with studies performed in Hong Kong, Japan and America. ${ }^{15,18,19}$ But in a Korean and some western population-based studies, the most frequent location of UC was proctitis. ${ }^{2,20}$ This discrepancy may be related to selection bias due to the fact that our study and some selected studies in Asia were hospital-based and may have not included all patients with mild UC. According to our data, the most commonly reported phenotype of CD was the behavior of penetrating type during 1995-2004, while during the 2005-2009, it was the behavior of non-penetrating and nonstricturing. This result is similar to an American study, in which the prevalence of the inflammatory phenotype was significantly greater than stricturing disease $(65 \%$ versus $16 \%$, OR $4.1,95 \%$ CI: $2.5-7.0$, $\mathrm{P}=0.001)$ or fistulizing disease ( $65 \%$ versus $19 \%$, or $3.4,95 \%$ CI: 2.1 $5.5, \mathrm{P}=0.001){ }^{21}$ This might be related to the development of economy and the level of medical care in the corresponding area. Patients may seek medical care earlier in the course of the disease before it gets complicated with penetrating or stricturing.

In our investigation, there was no significant change in the gender ratio and mean age at diagnosis during the past 15 years. The equal gender distribution for UC in our study was similar to the studies in Asia and western countries, whereas there appears to be male predominance for CD in China and in other Asian countries. This is in contrast to western studies that generally show an equal gender distribution or a moderate female predominance for $\mathrm{CD}$. The reasons for gender differences between Asian and western are unclear but may be related to smoking or genetic factors. The mean age at diagnosis of $\mathrm{UC}$ and $\mathrm{CD}$ was 48 years and 34 years respectively in our data. While in Western studies, UC is diagnosed most frequently in patients in the 30-40 year-old age group, but CD tends to be diagnosed most frequently in the 20-30 year-old group. ${ }^{22} \mathrm{We}$ found that the colectomy rate of UC was $7.6 \%$ without significant changes during the last 15 years. It is comparable to the long-term follow-up study of Hong Kong which showed the cumulative colectomy rates were $2.4 \%$ and $7.6 \%$ at 1 and 10 years of follow up. ${ }^{18}$ In a recent Korean study of UC cases diagnosed from 1989 to 2005 reported lower cumulative colectomy rates of $2.0 \%$ after 1 year, $2.8 \%$ after 3 years and 3.3\% after $5-15$ years. ${ }^{23}$ In South-Eastern Norway, the cumulative colectomy rate was $3.5 \%, 7.6 \%$, and $9.8 \%$ after 1,5 and 10 years. ${ }^{24}$ The rate of colectomy was significantly lower in China compared to some Western countries with colectomy rates of $3-10 \%$ after 1 year, $8-20 \%$ after 5 years, and $24-34 \%$ after 10 years. ${ }^{20}$ The colectomy rate of $\mathrm{CD}$ in our investigation showed a significant decreasing tendency from $32.3 \%$ in the period of $1995-2004$ to $18.4 \%$ in $2005-2009$, which was lower than the studies in Japan and western countries. A recent Japanese study reported that the cumulative colectomy rate of $\mathrm{CD}$ was $37.6 \%, 60.4 \%$ and $74.2 \%$ at 5,10 and 15 years after the onset of symptoms, respectively. ${ }^{25}$ In South-Eastern Norway, $28 \%$ of CD patients underwent intestinal resection during the 5 years follow up. ${ }^{26}$ In Olmstead County, Minnesota, $41 \%$ of CD patients underwent one or more surgical procedure during follow up. ${ }^{27}$ In western countries, the cumulative colectomy rate of $\mathrm{CD}$ was $40 \%, 60 \%, 70 \%$ and $90 \%$ at $5,15,20$ and 30 years respectively. ${ }^{25,28}$ The lower colectomy may be due to many reasons including the milder disease, the short duration of follow up, a better response to medical therapy, the reluctance attitude toward the colectomy by both patients and surgeons. The UC-related mortality was $0.4 \%$ in our investigation without any changes during past 15 years. The mortality tendency of UC was similar to North American. In Olmsted County, Minnesota in 1940-2004, the cumulative survival of UC were $93 \%, 85 \%, 72 \%$ and $59 \%$ after $10,20,30$ and 40 years. The cause specific mortality was not significantly increased in any subcategory. By contrast, a decreased mortality from cardiovascular disease was observed in UC. ${ }^{29}$ Our data showed the mortality of CD was $2.3 \%$, and was decreasing from period of 1995-2004 to 20052009, which is similar to a tendency observed in Olmsted County, Minnesota during 1940-2004. ${ }^{15,29}$ Meanwhile, we have noticed the GDP was increasing and the drug therapeutic status was improving, suggesting the improvement of health service and treatment strategies might contribute to the reduction of the CD-related mortality. The familial aggregation rates for UC and CD in our study were $0.4 \%$ and $1.7 \%$ respectively, without any significant changes during the study period, which is much lower than the reported rates ranging from $8 \%$ to $14 \%$ in western countries. ${ }^{20}$ A Korean study showed that the frequency of familial history may rise with time, in parallel with the increase in prevalence of IBD within the country. ${ }^{2}$ However, we did not find this trend in China.

Our results showed the drug treatment strategies were improving as standard treatments were implemented with the improved physician awareness and as new drugs were developed with the advanced research on pathogenesis of IBD. Various therapy options have been available. The curative effects have shift from improving symptoms to mucosal healing. For example, the novel biological agent, infliximab has been regularly used in studied hospitals since 2009, with 15 patients prescribed infliximab just in 2009. However our hospitalbased study has its limitations as it may have not included all patients with mild IBD and thus is less accurate than a population-based study. Though we have reported the medications, the prognosis of IBD needs further investigation.

\section{Conclusion}

In conclusion, during 1995-2009, the age, gender, location distribution and the familial occurrence of IBD did not change significantly in eastern China. The incidence in inpatients of CD 
has increased and significantly associated with the GDP growth. Whereas, the decreasing tendency of colectomy and mortality rates were similar to western countries, as standardized treatment of IBD are being implemented in China. This study provides insight into the possible local changing epidemiological and clinical patterns of IBD. But further population-based and long-term follow-up studies are still required in China to obtain nationwide epidemiological information.

\section{Acknowledgments}

None.

\section{Conflicts of interest}

The author declares there is no conflict of interest.

\section{References}

1. Olodecky Na, Soon Is, Rabi Dm,et al. Increasing Incidence And Prevalence Of The Inflammatory Bowel Diseases With Time, Based On Systematic Review. Gastroenterology. 2012;142(1):46-54 .

2. Yang SK, Yun S, Kim JH, et al. Epidemiology of inflammatory bowel disease in the Songpa-Kangdong district, Seoul, Korea, 1986-2005: a KASID study. Inflamm Bowel Dis. 2008;14(4):542-549.

3. Wang YF, Ouyang Q, Hu RW. Progression of inflammatory bowel disease in China. J Dig Dis. 2010;11(2):76-82.

4. Chow DK, Leong RW, Lai LH, et al. Changes in Crohn's disease phenotype over time in the Chinese population: validation of the Montreal classification system. Inflamm Bowel Dis. 2008;14(4):536541.

5. Leong RW, Lau JY, Sung JJ. The epidemiology and phenotype of Crohn's disease in the Chinese population. Inflamm Bowel Dis. 2004;10(5):646-651.

6. Lennard-Jones JE. Classification of inflammatory bowel disease. Scand J Gastroenterol Suppl. 1989;170:2-6.

7. Satsangi J, Silverberg MS, Vermeire S, et al. The Montreal classification of inflammatory bowel disease: controversies, consensus, and implications. Gut. 2006;55(6):749-753.

8. Wang Y, Ouyang Q; APDW. Chinese IBD working group (2007) Ulcerative colitis in China: retrospective analysis of 3100 hospitalized patients. J Gastroenterol Hepatol. 2004;22(9):1450-1455.

9. PDW2004 Chinese IBD Working Group. Retrospective analysis of 515 cases of Crohn's disease hospitalization in China: nationwide study from 1990 to 2003. J Gastroenterol Hepatol. 2006;21(6):1009-1015.

10. Loftus CG, Loftus EV Jr, Harmsen WS, et al. Update on the incidence and prevalence of Crohn's disease and ulcerative colitis in Olmsted County, Minnesota, 1940-2000. Inflamm Bowel Dis. 2007;13(3):254261.

11. Lakatos L, Mester G, Erdelyi Z, et al. Striking elevation in incidence and prevalence of inflammatory bowel disease in a province of western Hungary between 1977-2001. World J Gastroenterol. 2004;10(3):404409 .

12. olinié F, Gower-Rousseau C, Yzet T, et al. Opposite evolution in incidence of Crohn's disease and ulcerative colitis in Northern France (1988-1999). Gut. 2004;53(6):843-848.
13. Yoshida $Y$, Murata $Y$. Inflammatory bowel disease in Japan: studies of epidemiology and etiopathogenesis. Med Clin North Am. 1990;74(1):67-90.

14. Yang SK, Hong WS, Min YI, et al. Incidence and prevalence of ulcerative colitis in the Songpa-Kangdong District, Seoul, Korea, 19861997. J Gastroenterol Hepatol. 2000;15(9):1037-1042.

15. Loftus EV Jr, Silverstein MD, Sandborn WJ, et al. Crohn's disease in Olmsted County, Minnesota, 1940-1993: incidence, prevalence, and survival. Gastroenterology. 1998;114(6):1161-1168.

16. Wills-Karp M, Santeliz J, Karp CL. The germless theory of allergic disease: revisiting the hygiene hypothesis. Nat Rev Immunol. 2001;1(1):69-75

17. Cao Q, Si JM, Gao M, et al. Clinical presentation of inflammatory bowel disease: a hospital based retrospective study of 379 patients in eastern China. Chin Med J (Engl). 2005;118(9):747-752.

18. Chow DK, Leong RW, Tsoi KK, et al. Long-term follow-up of ulcerative colitis in the Chinese population. Am $J$ Gastroenterol. 2009;104(3):647-654.

19. Fujimoto T, Kato J, Nasu J, et al. Change of clinical characteristics of ulcerative colitis in Japan: analysis of 844 hospital-based patients from 1981 to 2000. Eur J Gastroenterol Hepatol. 2007;19(3):229-235.

20. Thia KT, Loftus EV Jr, Sandborn WJ, et al. An update on the epidemiology of inflammatory bowel disease in Asia. Am J Gastroenterol. 2008;103(12):3167-3182.

21. Malaty HM, Hou JK, Thirumurthi S. Epidemiology of inflammatory bowel disease among an indigent multi-ethnic population in the United States. Clin Exp Gastroenterol. 2010;3:165-170.

22. Loftus EV Jr, Sandborn WJ. Epidemiology of inflammatory bowel disease. Gastroenterol Clin North Am. 2002;31(1):1-20.

23. Park SH, Kim YM, Yang SK, et al. Clinical features and natural history of ulcerative colitis in Korea. Inflamm Bowel Dis. 2007;13(3):278-283.

24. Solberg IC, Lygren I, Jahnsen J, et al. Clinical course during the first 10 years of ulcerative colitis: results from a population-based inception cohort (IBSEN Study). Scand J Gastroenterol. 2009;44(4):431-440.

25. Oriuchi T, Hiwatashi N, Kinouchi Y, et al. Clinical course and longterm prognosis of Japanese patients with Crohn's disease: predictive factors, rates of operation, and mortality. $J$ Gastroenterol. 2003;38(10):942953.

26. Henriksen M, Jahnsen J, Lygren I, et al. Clinical course in Crohn's disease: results of a five-year population-based follow-up study (the IBSEN study). Scand J Gastroenterol. 2007;42(5):602-610.

27. Agrez MV, Valente RM, Pierce W, et al. Surgical history of Crohn's disease in a well-defined population. Mayo Clin Proc. 1982;57(12):747752 .

28. Yao T, Matsui T, Hiwatashi N. Crohn's disease in Japan: diagnostic criteria and epidemiology. Dis Colon Rectum. 2000;43(10 Suppl):S85S93.

29. Jess T, Loftus EV Jr, Harmsen WS, et al. Survival and cause specific mortality in patients with inflammatory bowel disease: a long term outcome study in Olmsted County, Minnesota, 1940-2004. Gut. 2006;55(9):1248-1254. 